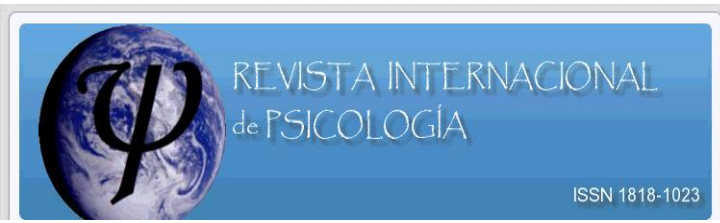

\title{
Entre el Amor Cortés y el Lugar del Analista
}

Lic. Alejandra Vartuli ${ }^{1}$

Si Uno sigue escribiendo sobre el amor es porque dos no hacen uno, el encuentro no llega y las palabras no cierran la brecha que abre el desencuentro.

Entre Uno y Otro, puentes de palabras que hablan de amor.

Escribimos porque sufrimos una desdicha de amor.

Recreamos la ilusión a repetición y terminamos sangrando por la herida. Maltrechos y hambrientos es como algunos llegan al consultorio a narrar una novela: dramática la más de las veces, trágica en el peor de los casos.

Novelan, cuentan mil historias de amor, en definitiva, una sola: aquella que en los comienzos, paradójicamente, les abrió la herida y los arrojó a la búsqueda vital del reencuentro.

Y si vienen a "contar" es porque lo toman a "uno" en serio, en serie. La ficción toma la escena y la reescritura se pone en marcha. Construimos una ficción dentro de otra, que es el dispositivo analítico. Vestimos los ropajes de aquel Otro que está todo el tiempo entre bambalinas, y nos aventuramos en una historia de amor que, ya sabemos, no tendrá final feliz. El encuentro fallido nos estará esperando y el engaño tendrá posibilidad de triunfo si seguimos los caminos del amor como coartada.

Sin embargo, nos disponemos a "ello" en nuestra oferta. ¿Qué amor o falta nos mueve a tal propósito?; en esa oferta de amor abstinente que hacemos como analistas en pos de la verdad del sujeto ¿qué modelo de amor recreamos?

Si no nos enredamos en las telarañas amorosas es porque nuestro interés está en otra "cosa". En la palabra, en las letras que la tejen, en los modos de decir, en las versiones del relato. Entonces, hablamos del amor como pretexto mientras seguimos las huellas del texto que se dice en otra escena.

Decires sobre el amor, en su mayoría, sintomáticos, repetitivos.

A diferencia de éstos, hubo un modo de decir sobre el amor que produjo un corte sincrónico en la diacronía histórica de la literatura: el amor cortés.

Muchas son las versiones que la historia de la literatura propone para entender qué fue el amor refinado. Versiones que sitúan el origen en la poética oriental y su desarrollo en el medioevo europeo como principal ejercicio de la corte, de donde tomará el nombre de amor cortés. Versiones que intentan responder ¿qué es el amor cortés?, ¿un modo de amar?, ¿una poética.? ... ¿una retórica, que en sus marcas significantes nos permite leer un modo de hacer el amor?

Lo cierto es que el amor cortés reunía condiciones particulares: la distancia con el objeto, siempre inalcanzable; al punto que Tomás Abraham nos comenta que esta poética no necesitaba del objeto amado, "cuanto más lejana era la dama o donoi, más se nutría el poema" y que "la satisfacción de amor deja de ser amor", interrumpe la

\footnotetext{
${ }^{1}$ Universidad Nacional de Buenos Aires. Correo electrónico: syc@ serviciosyclientes.com.ar
} 
escritura, el canto al amor. De otra manera, Denis de Rougemont dice que "el amor dichoso (satisfecho) no tiene historia", en la satisfacción no se hace una novela.

Otra condición es que el objeto perdía las características particulares, de manera que cualquier poema podía estar dirigido a la misma dama ya que no se encontraban rasgos singulares que pudieran diferenciarlas.

Entonces, en los obstáculos a la satisfacción, en los rodeos para alcanzar el objeto siempre distante, inaccesible, se organiza un modo de decir, se despliega una historia de amor, se escribe un Roman.

Modo de organización significante que teniendo en el centro a la Dama, la Mujer, logró delimitar el vacío, lo real, produciendo repercusiones éticas sobre las relaciones entre los sexos, y ejerciendo fuerte influencia en las costumbres de la época y de los tiempos posteriores.

En dicha estructura discursiva queda de manifiesto el objeto femenino como inaccesible y el presupuesto de una barrera que lo aísla y lo rodea. Queda vaciado de toda sustancia real, despersonalizado. El objeto amoroso deja de ser una persona para convertirse en una función simbólica. Sobre esta condición de inaccesibilidad se organiza el rodeo. Por esto podemos decir que las técnicas del amor cortés son un juego de rodeos, de suspensión, de obstáculos, y definen una erótica particular. Ya no importa qué objeto, sino el objeto elevado al lugar de "cosa" que causa un decir. Este modo de tratar lo real ha dado razón para entender la poética del amor cortés como un paradigma de la sublimación.

Amor abstinente, inaccesibilidad del objeto, lugar que causa un decir... y la escritura de una novela en los rodeos que intentan bordear el vacío.

B. llegó a la consulta con motivo de la separación de "un chico con el que salía". A partir de allí, se suceden "chicos" en una metonimia que parecía no detenerse. Todos "fallan", la desilusionan a pesar de su resistencia a ilusionarse. Desconfía, los pone a prueba, se "guarda" sus afectos, sus pensamientos, para no sufrir, en la ilusión de que en este modo si ellos fallan, ella no pierde nada.

B. no soporta el juego de los rodeos preliminares en sus relaciones, "las cosas son blanco o negro". Los tiempos de espera están colapsados, "hace cuatro días que no me llama, entonces quiere decir que no le interesa", los intervalos, las diferencias, producen en ella tanta ansiedad que se ve compelida a cerrar, tapar, obturar rápidamente.

Hace ya un año que B. está en tratamiento, no faltó nunca a sus entrevistas, y estamos en el recorrido que le permita entrar en un análisis.

Desde hace algún tiempo comencé a intervenir sobre la desconfianza y lo que B. se guarda; las intervenciones apuntan a conmover y movilizar la economía conservadora con la cual B. cree no perder nada, resguardándose en un "no puedo". Esto permite abrir un interrogante "¿por qué hago eso?"

Por primera vez, hace dos semanas trajo el relato de un sueño: soñó que "le sacaba el hijo" a una pareja que ella conoce, "ellos estaban desesperados porque les había sacado el hijo ... ¿será que quiero tener un hijo?" 
Tomo este sueño y otros indicios como efectos de la línea de intervención. Comienza a abrirse una brecha en la textura cerrada de su discurso. Brecha que también abre el camino a las facilitaciones de la repetición.

A la entrevista siguiente, B. pregunta cómo debe hacer si ella quiere pagar más por su tratamiento, "es que este mes me sobró y puedo". Está claro que B. no paga, ella intenta obturar la diferencia. El cambio en los honorarios está previsto para marzo, pero el cálculo es sobre la base de que a B. le falte, y podamos poner en juego esa diferencia. Por el momento, la táctica está orientada a sostener esta brecha, separación que comienza a producirse. La propuesta es que entremos en el rodeo, en el despliegue, en la escritura; para "ello" es necesario que las cuentas no cierren. B. cree que con un poco más de dinero podría salvar las diferencias. Por suerte, estamos en desacuerdo. Me abstuve, ante la propuesta ¿amorosa? respondí que por ahora no habría cambio en los honorarios.

No siempre es tan sencillo el camino que lleva de paciente a "trovador", ni de objeto-persona a la función de analista. El vacío se instala por el deseo de analista. Y en el esfuerzo de bordear ese vacío sin palabras, nuestros pacientes dicen y repiten. Y allí, cuando estamos por escuchar alguna palabra sobre la causa de tanta desdicha, nos hablan de amor. Es en ese instante en el que, conociendo las trampas del amor, la abstinencia, la no satisfacción permitirá que la novela se historice. Tiempo de espera que suspende el acto en pos de un porvenir. Apuesta a la producción de un texto que en sus torsiones, versiones, posibilite la emergencia de una porción de verdad, para ese sujeto perdido en las huellas de aquella primera historia de amor.

\section{Bibliografía}

Tomás Abraham: La guerra del amor. Editorial Planeta. Biblioteca Sur. Bs. As. 1992 Denis de Rougemont: Amor y occidente. Ed. Kairos, 1978

Jaques Lacan: Seminario VII. La ética del psicoanálisis.

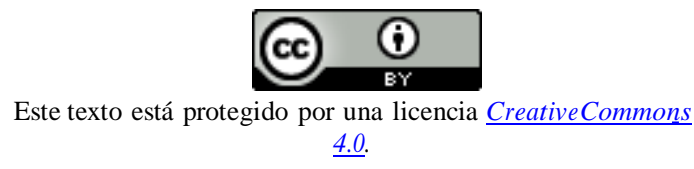

Usted es libre para Compartir — copiar y redistribuir el material en cualquier medio o formato - y Adaptar el documen- to -remezclar, transformar y crear a partir del material- para cualquier propósito, incluso comercialmente, siempre que cumpla la condición de:

Atribución: Usted debe reconocer el crédito de una obra de manera adecuada, proporcionar un enlace a la licencia, e in- dicar si se han realizado cambios. Puede hacerlo en cualquier forma razonable, pero no de forma tal que sugiera que tie-ne el apoyo del licenciante o lo recibe por el uso que hace. 